\title{
Prevalence of Toxoplasma Gondii in Women Population in Swat, Pakistan
}

\author{
Naseer Ullah ${ }^{1}$, Dil Nawaz ${ }^{1}$, Muzafar Shah ${ }^{1 *}$, Akhtar Rasool ${ }^{2}$, Fazal Akbar ${ }^{2}$ and Muhammad \\ Israr $^{3}$ \\ ${ }^{1}$ Centre for Animal Sciences and Fisheries, University of Swat, Pakistan \\ ${ }^{2}$ Centre for Biotechnology and Microbiology, University of Swat, Pakistan \\ ${ }^{3}$ Department of Forensic Sciences, University of Swat, Pakistan \\ *Corresponding author: Muzafar Shah, Centre for Animal Sciences and Fisheries, University of Swat, Pakistan
}

\section{ARTICLE INFO}

Received: 旐 September 02, 2020

Published: September 10, 2020

Citation: Naseer Ullah, Dil Nawaz, Muzafar Shah, Akhtar Rasool, Fazal Akbar, Muhammad Israr. Prevalence of Toxoplasma Gondii in Women Population in Swat, Pakistan. Biomed J Sci \& Tech Res 30(2)2020. BJSTR. MS.ID.004926.

\section{Keywords: $\quad$ Toxoplasma Gondii;} Toxoplasmosis; Prevalence; Abortion; Still Birth

\section{ABSTRACT}

Toxoplasma gondii is an obligate intracellular, parasitic protozoon causes toxoplasmosis. Toxoplasmosis is widely prevalent all over the world, infecting most of warm blooded animals including human. Serological studies estimate that $30-50 \%$ of the global human population is infected with T. gondii. Toxoplasmosis causes serious complications such as stillbirth, abortion, different problems like mental and physical retardation, blindness and hydrocephalus. In present study total 216 blood samples were collected from symptomatic females from different localities of District. For the detection of parasite, lateral flow immune-chromatographic assay strip was used. Overall prevalence rate was $25.92 \%$. The highest prevalence(33.33\%)was recorded in age group 31-40 years. Lowest prevalence(18.6\%)and (18.75\%) were observed in age groups 11-20 and 41-50 respectively. Tehsil Bahrain was more effected (47.72\%)while lowest prevalence(18.6\%) was observed in Tehsil Kabal. Lower class families had high prevalence rate $(34.32 \%)$ than upper class families (13.79\%). Women using spring water were more affected(47.36\%).Highest prevalence (43.93\%) was observed in the females who hadcats in their homes.28\% abortions and $21 \%$ still births were also observed in pregnant women. Special control measures and awareness in people is necessary, to reduce further spreading of toxoplasmosis in the area.

\section{Introduction}

Parasitic protozoans cause many diseases in human such as malaria, sleeping sickness, leishmaniasis, toxoplasmosis and Chagas disease. These are observed as being among the chief diseases of tropical countries and have threaten one quarter of the world's population [1]. Toxoplasmosis is a wide spread zoonotic disease transmitted from animals to humans and caused by a parasitic protozoan called Toxoplasma gondii and in the entire world about $30 \%$ population is infected [2]. Toxoplasma gondii belongs to the Kingdom Animalia, Phylum Apicomplexa, Class Protozoa, Subclass Coccidian, Order Eucoccidia, Family Sarcocystidae and Genus Toxoplasma [3]. Toxoplasma gondii is an intracellular and obligate parasite which affects many hosts. The definitive host of T. gondii are the wild felines and cats while the intermediate hosts are warm blooded animals including humans [4]. Humans become infected by eating of raw or poorly cooked meat or by using food or drink contaminated with infected cat faeces or by ingesting oocyst from surrounding environment [5]. Transimition through blood transfusions and organ transplantation is also observed in infected humans [6].

Through the milk of cattle, sheep, goats and sometimes through eggs of chicken infection can be occurred [7]. During pregnancy, toxoplasmosis can be transmitted through placenta in fetus [8]. During pregnancy toxoplasmosis can cause serious complications such as stillbirth, abortion and different degrees of physical or mental retardation, blindness and hydrocephalus [8]. Ocular disease usually retinochoroiditis develop in about 2\% healthy people having infection by T. Gondii [9]. Diseases like pneumonia, pericarditis, mental retardation, blindness, chorioretinitis, central 
nervous damage, hydrocephalus, meningoencephalitis, intracranial calcifications, and epilepsy or spontaneous abortion in about $10 \%$ of cases are also caused by $T$. gondii. Congenital infection cause lesions in the retina of the eye, which lead to loss of vision power and sometimes pain in the eyes [10]. Most of the people show no symptoms after birth, however some people suffer from mild disease or in rare cases more severe systemic illness [11]. Flu like illness or cervical lymphadenopathy may develop in $10-20 \%$ patients with acute infection [12].

Host tissue removed by biopsy or necropsy can be used for the diagnosis of T. gondii. Microscopic examination is a rapid diagnosis of impression smears of lesions [13]. PCR is used in molecular diagnosis [14]. Antibody detection is usually used for the diagnosis of toxoplasmosis. High frequency of IgG antibodies is an indication thatthe person is previously infected [15]. Detection of specific IgM antibodies show a recent infection. Human toxoplasmosis can be diagnosed typically using Indirect Fluorescent Antibody Testing (IFAT), Latex Agglutination Test (LAT), Immuno-chromatographic Test (ICT), or Enzyme Linked Immunosorbent Assay (ELISA) [15]. Toxoplasmosis infecting most genera of homoeothermic animals (more than 30 species of birds and 300 species of mammals). About $30-50 \%$ of the world human population is infected with this parasite [16]. Prevalence of toxoplasmosis is observed throughout the world from different localities except Antarctica [7]. Most of the cases are reported from France (88\%) followed Netherlands (80\%), Germany (68\%), and Brazil (67\%) [7].

In Europe about 30\% prevalence of toxoplasmosis is reported while across USA its prevalence rate is about 10\% [10]. In Pakistan overall prevalence rate of toxoplasmosis is $29.45 \%$ [17]. Prevalence in adult human population of Dera Ghazi Khan, Punjab, is $29.5 \%$ [9], while in district Mardan Khyber Pakhtunkhwa is 28.44\% [10]. In Pakistan the seroprevalence of T. gondii antibodies in pregnant women varies. Highest prevalence (63\%) was recorded from Punjab, followed by Azad Kashmir (48\%). Low prevalence was reported from Khyber Pakhtunkhwa with infection rate of 33.03\% and $14.4 \%$ from Dir Upper and Swabi respectively [18]. Aims of the current study was to find out prevalence of toxoplasmosis in local population, to determine the rate of abortion and still births in pregnant women and to find the risk factors of toxoplasmosis in district Swat.

\section{Materials and Methods}

\section{Study Area}

Swat is one of the districts of Khyber Pakhtunkhwa, Pakistan [19]. It is a lush green valley lying between $34^{\circ} 34^{\prime \prime}$ and $35^{\circ} 55^{\prime \prime}$ north latitudes and $72^{\circ} 08^{\prime \prime}$ and $72^{\circ} 50^{\prime \prime}$ East longitudes. The climate of Swat is somewhat warm and humid with short and moderate summers; temperature seldom rises above $37^{\circ} \mathrm{C}$ [20]. Swat is surrounded by Chitral, Upper Dir and Lower Dir in the West, Gilgit
Baltistan in North, Kohistan, Buner and Shangla in the East and southeast [19]. Swat district is subdivided into seven tehsils; Tehsil Babuzai, Tehsil Matta, Tehsil Khwaza Khela, Tehsil Barikot, Tehsil Kabal, Tehsil Charbagh and Tehsil Bahrain.

\section{Samples Collection}

This study was conducted during June to September 2016. 300 blood samples (2-3 ml) were collected using disposable syringes from symptomatic individuals belongs to different localities of District Swat. After collection, blood was transferred to EDTA tubes and the tubes were stored at low temperature until diagnosis.

\section{Laboratory Procedure}

The detection of T. gondii in present research was done by in-Site Toxo IgG/IgM rapid test, which is a lateral flow chromatographic immunoassay.

\section{Results}

In present study total 216 blood samples were collected from females of different localities of District Swat. Over all prevalence of toxoplasmosis was 26\% (Figure 1). The highest prevalence of toxoplasmosis was recorded in Tehsil Bahrain (47.72\%), followed by Barikot (23.07\%), Babuzai (22.22\%), Khwaza khela(20\%), Matta (19.23\%) and Charbagh (19.04\%), and Kabal (18.6\%) was observed in Tehsil Kabal (Figure 2). Age wise prevalence was also observed. Highest prevalence 33.33\% (30/110) was recorded in age group 31-40 years, followed by $30 \%(33 / 110)$ in age group 21 30 years. Low prevalence $18.6 \%$ (8/43)and 18.75\% (3/16) were observed in age groups 11-20 and 41-50 respectively (Figure 3).

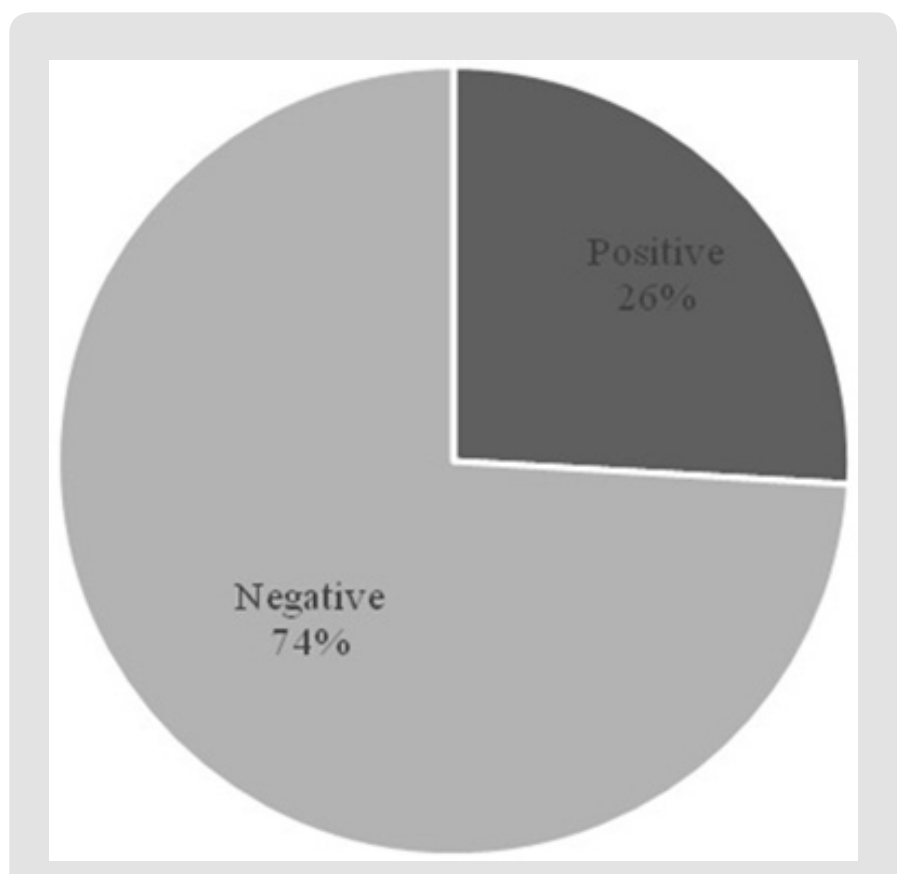

Figure 1: Overall prevalence of toxoplasmosis. 


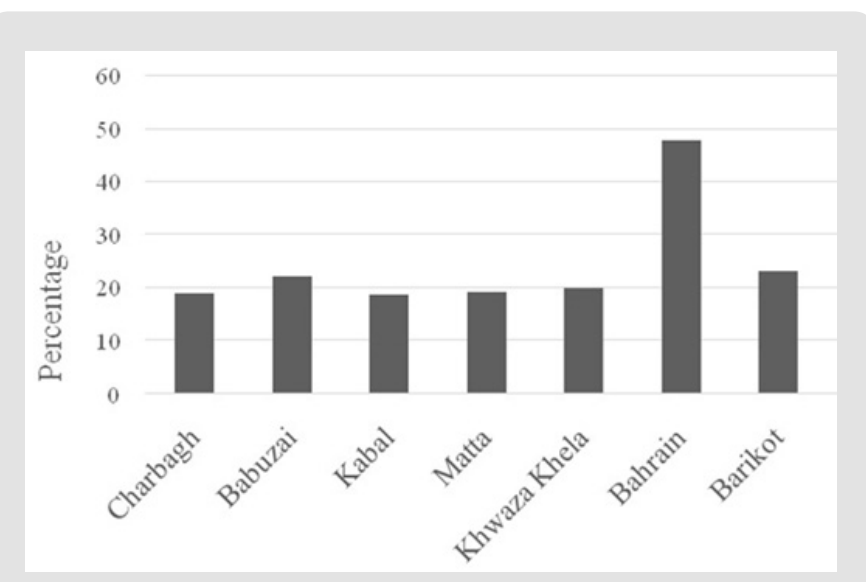

Figure 2: Tehsil wise prevalence of toxoplasmosis.

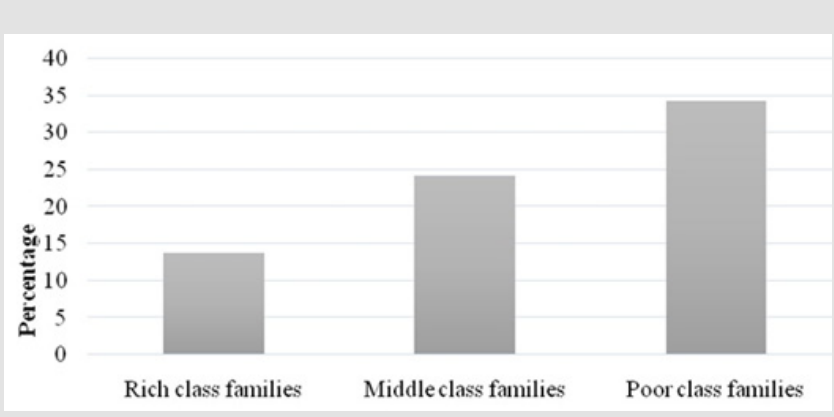

Figure 3: Prevalence of toxoplasmosis in females with different socioeconomic status.

The result show that Lower class families were highly effected (34.32\%), followed by middle (24.16\%) and upper class $(13.79 \%)$ (Figure 3). Toxoplasmosis is a very dangerous zoonotic infectious disease which can cause serious complications in pregnant women. Along with other pathogenic infections toxoplasmosis is also one of the possible cause of abortion. The abortion rate in pregnant women was $28 \%$. Toxoplasma gondii can cross placenta, reach to fetus and cause serious complicated congenital problems like still birth, blindness, hydrocephaly, mental and physical retardations etc. During our present study $21 \%$ females were found who have experienced still births (Table 1). Risk factors were also observed. Possible ways of infection in the patients were contact with cats and cattle, use of unpasteurized milk, use raw/poorly cooked meat and use of unwashed fruits and vegetables (Table 2).

Table 1: Prevalence of abortion and still birth in the females of District Swat.

\begin{tabular}{|c|c|}
\hline Complications of Toxoplasmosis & Percentage \\
\hline Abortion & $28 \%$ \\
\hline Still Birth & $21 \%$ \\
\hline
\end{tabular}

Table 2: Risk factors for toxoplasmosis.

\begin{tabular}{|c|c|}
\hline Risk Factors & Positive Cases \\
\hline Cat Contact & $43.93 \%(29 / 66)$ \\
\hline Cattle Contact & $32.72 \%(36 / 110)$ \\
\hline Use of Unpasteurized Milk & $41.53 \%(27 / 65)$ \\
\hline Use of Raw/ Poorly Cooked Meat & $32.25 \%(30 / 93)$ \\
\hline Use of Unwashed Fruits and Vegetables & $28.18 \%(42 / 149)$ \\
\hline
\end{tabular}

\section{Discussion}

In present study total 216 blood samples were collected from symptomatic individuals of local human female population of district Swat. Overall prevalence of toxoplasmosis was $25.92 \%$ same result was shown by [8] while conducted a research on toxoplasmosis in Southern Punjab, Pakistan. Highest prevalence $33.33 \%$ (30/110) was recorded in age group 31-40 years, followed by $30 \%(33 / 110)$ in age group 21-30 years. Lowest prevalence $18.6 \%(8 / 43)$ and $18.75 \%(3 / 16)$ were observed in age groups 11-20 and 41-50 respectively in present research. Hayat $S$, et al. [2] Tested 150 samples and found the parasite in all age groups (range 1 to 70 years). They noticed highest prevalence (68.75\%) in age group 41-50 years, followed by $60 \%$ in age group of 1-10 years, $50 \%$ in age group 31-40 years and 61-70 years. intermediate prevalence $33.33 \%$ was found in age group 51-60 years. In age group 11-20 years lowest prevalence (19.35\%) was observed. Our result is somewhat similar with this finding. Data was also collected from different localities of seven Tehsils of district Swat.

The highest prevalence was recorded in Tehsil Bahrain 47.72\% (21/44), followed by Tehsil Barikot 23.07\% (6/26), Tehsil Babuzai 22.22\% (8/36), Tehsil Khwazakhela 20\% (4/20), Tehsil Matta $19.23 \%(5 / 26)$ and Tehsil Charbagh 19.04\% (4/21). Lowest prevalence $18.6 \%(8 / 43)$ was observed in Tehsil Kabal. High prevalence in Tehsil Bahrain may be due to multiple reasons, as this area is mostly rural and mountainous, climate is quite sound for sporulation of oocyst, financially these are mostly poor and middle class families, their hygienic conditions are not better, literacy rate is very low, mostly these women practice agricultural activities, majority of them living in muddy houses thus having more contact with the soil and also their contact with domestic animals is more. During present study toxoplasmosis in females with different socioeconomic status like rich, middle and poor was also investigated. The result showed that poor class families (34.32\%) were greatly effected as compare to middle $(24.16 \%)$ and upper class families (13.79\%).The findings are similar with the findings of [21].

Both research revealed that Seroprevalence rate is higher in the women belonging to the lower socioeconomic strata. The reason for high prevalence in lower class families may be due to their 
unhygienic conditions, low literacy rate, less or no awareness about the disease, more contact with cattle and agricultural practice. Abortion rate and still births are the possible complications in the pregnant women. Study revealed 21\% (46/216) females had still births, while $28 \%$ ( 61 out of 216 ) females were aborted in the study area. Previously Khan SN, et al. [22] reported that toxoplasmosis leads to still birth, abortion, anaemia, anorexia, etc. The study Elhag, et al. [23] also determined that toxoplasmosis can cause abortion and still birth. All the research shows similarities. Cats are the only definitive hosts of T. gondii where it complete sexual life cycle. Infected cats are very important because the oocysts secreted by cats are resistant to harsh environmental conditions, which can be reach to humans and cause serious complications. In present survey highest prevalence $43.93 \%$ (29/66) was observed in the females who have cats in their homes.

Previously Agmas, et al. [24] conducted a study on seroprevalence of Toxoplasma gondii infection and associated risk factors among pregnant women in Debre Tabor, Northwest Ethiopia. They determined that cat is major risk factor. The findings of the said researchers shows that people having cats in their homes were effected. Infection rate of $T$. gondii in pregnant women were 3.36 times more who have cats at their homes. The possible reason for more infection due to cat presence in the homes may be due to the access of cat faeces (which contain oocyst) to drinking and eating materials. In another study conducted by Imam, et al. [25] on "Seroprevalence of Toxoplasma gondii among pregnant women in Almadinah Almunawwarah KSA". In their study, there were no significant relation between Toxoplasmosis prevalence and the risk factor of having cats at homes. Sometimes cat may not be the transmission source of infection, there are many other factors like consumption of raw meat, use of unwashed fruits/vegetables, poor hygienic conditions and favorable climate for oocyst sporulation are also involved in the spread of disease. Prevalence of toxoplasmosis based on the presence or absence of domestic animals was also observed. The highest prevalence 32.72\% (36/110) was reported in women having cattle in their homes.

Brandon Mong, et al. [26] conducted a study on "Seroepidemiology of toxoplasmosis among people having close contact with animals". Total 312 blood samples were collected from veterinary personnel (veterinarian, technicians, and students) and pet owners from veterinary clinics and hospitals in the area of Klang Val-ley, Malaysia. Overall prevalence of toxoplasmosis was observed in 62 (19.9\%) participants in which 7 (18.4\%) were veterinarians, 15 (33.3\%) were veterinary technicians, 29 (14.9\%) were veterinary students, and pet owners were 11 (31.4\%). This study revealed that people having more contacts with animals are at higher risk of infection. Both the results are similar. One of the major source of infection of toxoplasmosis is use of poorly cooked or raw meat, as tissue cyst is found in the meat. Prevalence rate was higher $32.25 \%$ (30/93) in women who used raw or poorly cooked meat. Negash et al. [27] determined prevalence of toxoplasmosis, its zoonotic importance and possible factors related with its prevalence. Result revealed that $60 \%$ samples were seropositive. Result shown that people who have consumed raw or poorly cooked meat and have cats in their homes were at high risk. Our result is quite similar with the findings of Negash, et al. [27].

Many of the people do not cook meat properly and utilize this meat due to which they have more chances of infection. Uses of unpasteurized milk and unwashed fruits/vegetables are also the sources of transmission of toxoplasmosis. Women used unpasteurized milk have higher prevalence (41.53\%) than women who have not used unpasteurized milk $19.20 \%$. Prevalence was higher (28.18\%) in females who have used unwashed fruits/ vegetables compared to females $(20.89 \%)$ who have not used unwashed fruits/vegetables. Similar results were also found out by Majid, et al. [18]. They observed highest prevalence in the women who have consumed unpasteurized milk and unwashed fruits/ vegetables. e due to some factors, as Swat contain many rural areas and majority of these people keeping cattle in their homes and also drink unpasteurized milk. The higher prevalence of infection may be the reason that most of the people don't washed fruits and vegetables, as most of the people have mind-set that if fruits and vegetables are not washed, it cannot be a big problem for their heaths.

\section{Conclusion and Recommendations}

The present study concluded that in District Swat toxoplasmosis is prevalent in females which lead to complications such as still birth and abortions. It is also concluded that most of the people are unaware from the infections, their risk factors and complications. So, it is recommended that public awareness is necessary to minimize the infection in Swat.

\section{References}

1. Cox F (1993) Parasitic protozoa. Modern Parasitology: A Textbook of Parasitology, (2 $2^{\text {nd }}$ Edn.), p. 1-23.

2. Hayat S, Tasawar Z, Akhtar T (2014) Seroprevalence of human toxoplasmosis in Kallarwali village of district Muzaffar Garh, Pakistan. Gomal Journal of Medical Sciences 12: 129.

3. Dubey JP (2008) The history of Toxoplasma gondii-the first 100 years. Journal of Eukaryotic Microbiology 55(6): 467-475.

4. Mohammed TK (2011) Seroprevalence of Toxoplasma gondii among pregnant women in Baghdad city. AL-TAQANI 24(4): 21-28.

5. Jiang C, Li Z, Chen P, Chen L (2015) The seroprevalence of Toxoplasma gondii in Chinese population with cancer: a systematic review and metaanalysis. Medicine 94(50): e2774.

6. Gunn A, Pitt SJ (2012) Parasitology: An integrated approach: John Wiley \& Sons.

7. Uttah E, Ogban E, Okonofua C (2013) Toxoplasmosis: A global infection, so widespread, so neglected. IJSRP 3(6): 1-6.

8. Saki J, Mohammadpour N, Moramezi F, Khademvatan S (2015) Seroprevalence of Toxoplasma gondii in women who have aborted in comparison with the women with normal delivery in Ahvaz, southwest of Iran. The Scientific World Journal, 2015: 764369. 
9. Tasawar Z, Aziz F, Lashari MH, Shafi S, Ahmad M, et al. (2012) Seroprevalence of Human toxoplasmosis in southern Punjab, Pakistan. Pak J Life Soc Sci 10(1): 48-52.

10. Mahmood ZU, Zahid M, Sthanadar AA, Shah M, Hussain A (2014) Seroprevalence of Toxoplasma gondii infection in Gallus domesticus of District Mardan, Khyber Pakhtunkhwa, Pakistan. Pakistan J Zool 46(6): 1705-1710.

11. Dubey J, Jones J (2008) Toxoplasma gondii infection in humans and animals in the United States. International journal for parasitology 38(11): 1257-1278.

12. Mc Auley JB (2014) Congenital toxoplasmosis. Journal of the Pediatric Infectious Diseases Society 3(Suppl_1): S30-S35.

13. Hill D, Dubey J (2002) Toxoplasma gondii: transmission, diagnosis and prevention. Clinical microbiology and infection 8(10): 634-640.

14. Sensini A (2006) Toxoplasma gondii infection in pregnancy: opportunities and pitfalls of serological diagnosis. Clinical Microbiology and Infection 12(6): 504-512.

15. Gyang VP, Akinwale OP, Lee YL, Chuang TW, Orok A, et al. (2015) Toxoplasma gondii infection: seroprevalence and associated risk factors among primary schoolchildren in Lagos City, Southern Nigeria. Revista da Sociedade Brasileira de Medicina Tropical 48(1): 56-63.

16. Flegr J, Prandota J, Sovičková M, Israili ZH (2014) Toxoplasmosis-a global threat. Correlation of latent toxoplasmosis with specific disease burden in a set of 88 countries. PloS one 9(3): e90203.

17. Daryani A, Sarvi S, Aarabi M, Mizani A, Ahmadpour E, et al. (2014) Seroprevalence of Toxoplasma gondii in the Iranian general population: a systematic review and meta-analysis. Acta tropica 137: 185-194.

18. Majid A, Khan S, Jan AH, Taib M, Adnan M, et al. (2016) Chronic toxoplasmosis and possible risk factors associated with pregnant women in Khyber Pakhtunkhwa. Biotechnology \& Biotechnological Equipment 30(4): 733-736.

\section{ISSN: 2574-1241}

DOI: $10.26717 / B J S T R .2020 .30 .004926$

Muzafar Shah. Biomed J Sci \& Tech Res

(C) This work is licensed under Creative Commons Attribution 4.0 License

Submission Link: https://biomedres.us/submit-manuscript.php
19. Bangash S (2012) Socio-economic conditions of post-conflict Swat: a critical appraisal. J Peace Dev 2: 66-79.

20. Khan J, Khan I, Amin I (2016) A comprehensive entomological, serological and molecular study of 2013 dengue outbreak of Swat, Khyber Pakhtunkhwa, Pakistan. PloS one 11(2): e0147416.

21. Rosso F, Les JT, Agudelo A, Villalobos C, Chaves JA, et al. (2008) Prevalence of infection with Toxoplasma gondii among pregnant women in Cali, Colombia, South America. The American journal of tropical medicine and hygiene 78(3): 504-508.

22. Khan SN, Khan S, Ayaz S, Jan A, Jehangir S, et al. (2011) Seroprevalance and risk factors of toxoplasmosis among pregnant women in District Kohat, Khyber Pakhtunkhwa, Pakistan. World Applied Sci J 14(7): 10321036.

23. Elhag BKE, Elturabi SEM (2015) Seroprevalence of toxoplasmosis among women with abortion in Khartoum State. Journal of Coastal Life Medicine 3(7): 551-554.

24. Agmas B, Tesfaye R, Koye DN (2015) Seroprevalence of Toxoplasma gondii infection and associated risk factors among pregnant women in Debre Tabor, Northwest Ethiopia. BMC research notes 8(1): 107.

25. Imam NF, Esra'a A, Attia AA (2016) Seroprevalence of Toxoplasma gondii among pregnant women in Almadinah Almunawwarah KSA. Journal of Taibah University Medical Sciences 11(3): 255-259.

26. Brandon Mong GJ, Seri CM, Anati NA, Sharma RSK, Andiappan H, et al (2015) Seroepidemiology of toxoplasmosis among people having close contact with animals. Frontiers in immunology 6: 143.

27. Negash T, Tilahun G, Medhin G (2008) Seroprevalence of Toxoplasma gondii in Nazareth town, Ethiopia. East Afr J Public Health 5(3): 211 214. 